\title{
A Study of the Predictors of Breastfeeding Self- Efficacy in Mothers During the Covid-19 Pandemic
}

Maryam Ahmad Zadeh Beheshti

Qazvin University of Medical Sciences

\section{Zainab Alimoradi}

Qazvin University of Medical Sciences

Nasim Bahrami ( $\square$ nbahrami87@gmail.com )

Qazvin University of Medical Sciences https://orcid.org/0000-0001-8751-6832

\section{Research}

Keywords: breastfeeding, Covid-19, self-efficacy

Posted Date: February 25th, 2021

DOl: https://doi.org/10.21203/rs.3.rs-246918/v1

License: (1) This work is licensed under a Creative Commons Attribution 4.0 International License. Read Full License 


\section{Abstract}

Background and Purpose: Breastfeeding has a vital role in ensuring the health of mother and infant, and ultimately the health of society. Breastfeeding self-efficacy is a strong predictor of the duration of breastfeeding, which in a variety of situations - including crises - may be affected by a number of factors. The aim of this study is to determine the predictors of breastfeeding self-efficacy in breastfeeding mothers during the Covid-19 pandemic.

Materials and Methods: A cross-sectional study was conducted with the participation of 300 breastfeeding mothers whose children were breastfed during the Covid-19 pandemic. Sampling was based on convenience sampling and online method using a checklist of personal and social characteristics and breastfeeding self-efficacy questionnaires, spouse postpartum social support, perceived social support, anxiety and depression, and fear of Covid-19. Data were analyzed using Pearson correlation coefficient, one-way ANOVA and multi variable linear regression model via stepwise method. Significance level in this study was considered to be 0.05 .

Results: The mean breastfeeding self-efficacy score among participants was $58.19 \pm 10.48$ (out of 70 ). Spouse postpartum social support $(\beta=0.732, p=0.04)$, intention to breastfeed $(p=0.001, \beta=0.17)$, use of formula while breastfeeding $(\beta=-0.09, p<0.001)$, and depression $(\beta=-0.11, p<0.001)$, were predictors of breastfeeding self-efficacy. But fear of Covid-19 was not significantly correlated with breastfeeding self-efficacy $(p=0.514)$.

Conclusion: The results of the present study showed that spouse postpartum social support and having the intention of breastfeeding with a positive effect; and depression and simultaneous use of formula in feeding the infant with a negative effect; are predictors of women's breastfeeding self-efficacy during the Covid-19 pandemic. It seems that breastfeeding can be improved by counseling to improve receiving the spouse support, increasing the breastfeeding intent, and reducing the depression.

\section{Introduction}

The World Health Organization (WHO) recommends breastfeeding initiation in the first hour after birth, exclusive breastfeeding for up to 6 months, and then, continuing breastfeeding until the child is 2 years old (1). Health organizations, including Centers for Disease Control and Prevention (CDC), WHO, and American Academy of Pediatrics (AAP), recommend exclusive breastfeeding for the first 4 to 6 months after birth (2). According to studies, a large percentage of women start exclusive breastfeeding after childbirth, but this rate decreases as the infant grows older $(3,4)$. The exclusive breastfeeding rate in Iran at national level has been reported as $56.8 \%$ after four months and $27.7 \%$ after six months. One of the goals of global nutrition policies is to increase exclusive breastfeeding in the first 6 months after childbirth by at least $50 \%$ by 2025 (5).

An approach to achieve this goal is to focus on the factors that affect mothers' breastfeeding. Based on studies, many factors such as age, marital status, education level, income, smoking, type of delivery, 
previous breastfeeding experience, decision to choose breastfeeding method, intention to return to work, ethnic and religious backgrounds, desire to become pregnant, social support and domestic violence are related to exclusive breastfeeding $(6,7)$. An important factor in the continuation of breastfeeding is a sense of self-efficacy in breastfeeding mothers (8). Breastfeeding self-efficacy is defined as the mother's confidence in her own capability to breastfeed her infant (9) and it is one of the factors affecting the continuation of breastfeeding during the first 6 months after delivery $(4,10)$. Self-efficacy is one of the constructs of Bandura's social cognitive theory (1997), which includes belief and confidence in one's ability to perform healthy behaviors, including exclusive and successful breastfeeding. Dennis believes that increasing breastfeeding self-efficacy in mothers will have a significant relationship with increasing the duration of exclusive breastfeeding (11). According to Bandura's theory, breastfeeding self-efficacy is affected by four main sources of information, including: previous breastfeeding experience, observing successful breastfeeding women, fatigue, stress, anxiety, encouragement by influential people including friends, family and previous counseling (12). Also, low self-esteem of mother might create an excessive sense of responsibility which she cannot handle and it will be a hindrance to her successful breastfeeding (13).

Physical, mental and social conditions are among the factors that affect the self-efficacy of breastfeeding mothers (8) and it is also affected by numerous factors such as mother's level of education, social support, delivery method, satisfaction of painless delivery, satisfaction of postpartum care, mother's understanding of the process of breastfeeding, the method adopted by mother to feed the baby and the mother's anxiety (14). However, these findings have not been confirmed in all studies. Some of them showed that there was no relationship between mother's age and job with breastfeeding selfefficacy $(15,16)$ and that the education level, mother's job, and previous breastfeeding experience have no effect on exclusive breastfeeding (17). In another study, age, alcohol consumption, the family history of asthma, allergies and eczema; place of delivery and place of postnatal ward, had no effect on exclusive breastfeeding in the third month after delivery (18). Effective psychological factors such as depression, anxiety, stress and self-esteem have been reported, and the results of studies in this field are also contradictory (17). A number of studies are being conducted in this regard and they are constantly searching for a strategy to improve and increase this major factor (3).

The world is currently embroiled in a new pandemic called Covid-19, which has affected all aspects of people's lives around the world (19). With the increase in infection cases and mortality rates, people's worries have increased significantly. In addition, the fear of encountering people who are at risk of catching Covid-19 has increased (20). Covid-19 and its consequences have led to fear, anxiety and worry among people around the world. A study by Lane et al., reported the fear of contact with individuals who may be infected with Covid-19 (21). A salient feature of infectious diseases compared to other conditions is fear, which is directly related to the transmission rate as well as complications and mortality rate. This leads to other social and psychosocial challenges such as stigma, discrimination and misguidance (2224). A study conducted following the HIV epidemic in Ethiopia found that HIV-positive mothers developed a widespread fear of breastfeeding, which led them to avoid breastfeeding and feel guilty. Fear of 
breastfeeding, which seems to have arisen following the outbreak among infected counselors and mothers, might challenge a well-established breastfeeding culture (25).

One of the most important concerns of mothers is to maintain the health of their children, which in conditions such as the Covid-19 pandemic may be disrupted and may even lead to the mother stopping breastfeeding. Pregnant and lactating mothers are a vulnerable group and need evidence-based advice to protect the health of mother and child. Adequate practical, psychological and social assistance should be provided to the breastfeeding mothers. All infants born to mothers infected with Covid-19 or suspected to be so, should be breastfed (26). According to the global importance of exclusive breastfeeding and the provided statistics and since breastfeeding self-efficacy has a significant impact on breastfeeding status and since many factors can affect breastfeeding self-efficacy, and also because there has not been a study to investigate the factors affecting breastfeeding self-efficacy in Covid-19 pandemic conditions so far, this study aims to identify the factors that can affect the self-efficacy of breastfeeding mothers during the Covid-19 pandemic. This study seeks to establish the published evidence on the subject so that health care workers can provide proper advice to breastfeeding mothers.

\section{Methods}

\section{Design and Participants}

The present research is a cross-sectional study that was conducted between Junes to November 2020 with the participation of breastfeeding women who had breastfed their babies during the onset of the coronavirus pandemic in the city of Qazvin.

\section{Sample size estimation}

The Green's (27) rule of thumb was used to determine the sample for linear multi variable analysis. Considering 35 predictor variables $(\mathrm{K})$, the sample size was calculated to be 330 persons.

\section{Sampling procedure}

In this study, we referred to five comprehensive health centers and specialized obstetrics and gynecology training hospital in the city of Qazvin that had the highest number of clients. We used a convenience sampling method. That is, by referring to the comprehensive health center and Kosar hospital in the city of Qazvin, breast feeding mothers with during the covid-19 pandemic who were willing to participate in the study were selected, and mothers who fed their children with only formula from birth, as well as those who did not answer the questionnaire completely ( 6 out of 330 persons) were excluded from the study.

\section{Measures \& Variables}

In the present study, breastfeeding self-efficacy was the dependent variable, and the variables of spouse postpartum social support, perceived social support, anxiety and depression, and fear of Covid-19 were the main independent variables. In addition, demographic and reproductive characteristics and 
coronavirus infection status were studied as covariates. The tools used for this study, which have gone through the psychometric process of the Persian version and are valid and reliable, consisted of the following items:

A checklist of personal, family, social and reproductive characteristics: This questionnaire includes questions such as age, level of education and occupation of the woman and her spouse, mother's understanding of the family's economic status, number of pregnancies and number of live children, pregnancy rank, desire for the current pregnancy (from the perspective of the woman and her spouse), type of delivery, infant's gender, skin-to-skin contact, previous breastfeeding experience, time of first breastfeeding, history of hospitalization of the baby and its cause, infant's age, and the birth status of the baby (pre-term, term and post-term). This questionnaire was developed by researchers and professors.

Spouse Postpartum Social Support Questionnaire: This scale was introduced in 2017 by Dennis et al. It has 20 items with a 4-point Likert scale responses from Strongly Disagree to Strongly Agree. The final score is calculated as the total score of the items, which varies between 20 and 80 . A higher score indicates more social support from the spouse. This questionnaire was developed based on the theoretical model of social relations and functional components of social support. The content validity was verified based on expert opinion. Psychometric evaluation, including internal stability analysis, exploratory factor analysis (EFA), and concurrent and predictive reliability and validity, showed that the psychometric properties of the English version are reasonable. The Cronbach's alpha for this scale was 0.96 (28). Eslahi et a/ provided the Persian version and the psychometric properties of this scale. Confirmatory factor analysis and analysis based on Rasch linear model and concurrent validity, confirmed the acceptable validity of this tool. In addition, Cronbach's alpha coefficient of 0.94 and the reasonable correlation between items, confirmed the acceptable reliability of this tool (29).

\section{Multidimensional Perceived Social Support Scale (MSPSS) Questionnaire: The Multidimensional} Perceived Social Support Scale by Zimet et al. was used to measure the perceived social support (30). This tool has 12 items based on the Likert scale from 1 (Highly Disagree) to 7 (Highly Agree) that measures the support that the person receives from the three sources of family, friends and important people in life. The range of scores obtained from this scale is 12 to 84 . The Cronbach's alpha of the total scale and also the subscales ranged from 0.85 to 0.91 and its reliability was reported through retesting as 0.72 to 0.85 (31). Psychometric properties of this questionnaire were examined by Salimi et al. Cronbach's alpha coefficients of the three dimensions of social support received from family, friends and important people in life were $89 \%, 86 \%$ and $82 \%$, respectively; which confirmed the reasonable reliability of the Persian version (32).

Anxiety and depression questionnaire: In the present study, the Hospital Anxiety and Depression Scale (HADS) Questionnaire was used to assess the anxiety and depression. HADS was developed in 1983 by Zigmond and Snaith to diagnose anxiety and depression disorders in patients in non-psychiatric clinics. This scale has 14 questions in two subscales of anxiety and depression. Each item is rated based on a 4point Likert scale from 0 to 3 . The maximum score that can be obtained in each subscale is 21 . Scores 
above 11 in each of the subscales mean having a significant psychological illness, scores from 8 to 10 indicate borderline cases, and scores from 0 to 7 are considered normal (33). Bjelland et al. (2002) examined the psychometric properties of HADS in a systematic review. They concluded that this tool is an appropriate tool for assessing anxiety and depression disorders for different groups, including somatic patients, psychotherapy patients, primary care unit clients and the general population (34). Psychometric properties of the Persian version were reviewed and confirmed by Montazeri et al. (2003) (35).

Fear of Covid-19 Questionnaire: This questionnaire was designed by Pakpour et al. In 2020. The tool consists of 7 questions. Participants express their level of agreement using a 5-point Likert scale. Answers include strongly disagree, disagree, neither agree or disagree, agree and strongly agree. The minimum possible score for each question is 1 and the maximum is 5 . The total score is calculated by adding the scores of each question (from 7 to 35). A higher score indicates a greater fear of the Covid-19. Psychometric properties of this tool have been approved for the Persian version in the Iranian population (36).

Breastfeeding Self-Efficacy Questionnaire: The breastfeeding self-efficacy questionnaire has 14 items, and it begins with positively loaded questions with the prefix I can always, and it is rated based on a 5point Likert scale from Always or I am completely sure (score 5) to Never or I am not completely sure (score 1). The lowest and highest scores are 14 and 70, respectively, such that the highest score indicates the highest level of breastfeeding self-efficacy $(37,38)$. The validity of this questionnaire has been reviewed and confirmed in a study by Varai et al. (16). The reliability of this questionnaire has been investigated in a study by Bastani et al. and a Cronbach's alpha of 0.87 has been obtained (39).

\section{Ethical Considerations}

The implementation of this research has been approved by Qazvin University of Medical Sciences with the ethics code IR.QUMS.REC.1399.079. Initially, breastfeeding women who met the research inclusion criteria were contacted via telephone and the study objectives and working methods were explained. If they wished to participate in the research, the link to the online questionnaire would be sent to them. In

order to observe ethical principles of the research, they were convinced that the information of individuals remained confidential and questionnaires were collected anonymously. The contents of the informed consent were listed on the first page of the online questionnaire and the continuation of the questionnaire completion process was considered as consent to participate in the study.

\section{Statistical Analysis}

In this study, 324 persons participated. The research data were analyzed using SPSS software, version 24. Mean and standard deviation were reported to describe continuous quantitative variables, and frequency and percentage were reported to describe qualitative variables. First, the normality of the distribution of breastfeeding self-efficacy scores was evaluated and confirmed using central distribution and dispersion indices, histogram graph, and Shapiro-Wilk Test. 
In the first step, one-way analysis of variance (ANOVA) and Pearson correlation coefficient were used to examine the association between breastfeeding self-efficacy as a dependent variable and independent variables of the study including spouse postpartum social support, perceived social support, anxiety and depression, fear of Covid-19, Covid-19 infection status, and the demographic and obstetric characteristics. Considering a significance level of 0.05 , the variables that had a significant correlation with breastfeeding self-efficacy were selected to be included in the multivariable linear regression model. These variables included spouse postpartum social support, breastfeeding intention, type of infant feeding, social support of the family, and depression.

Afterwards, the multivariable linear regression model was developed by considering the total score of breastfeeding self-efficacy as the dependent variable, and the above variables as independent variables. Multivariable regression model was based on stepwise method. Assumptions of using linear regression method including normal distribution of breastfeeding self-efficacy scores and lack of outlier data. In the initial model, given VIF $>10$ to examine the collinearity between independent variables, the family social support variable $(\mathrm{VIF}=25.9)$ was removed from the model. After removing this variable, the problem of collinearity between the independent variables in the model was resolved.

\section{Findings}

In this study, 324 women with a mean age of 29.68 (5.66) years and the spouse mean age of $34.27(5.47)$ participated. The majority of women 155 (47.8) and their spouses 137 (42.3) had university education. The majority of participants 280 (86.4) were housewives. The scores for mean and standard deviation of breastfeeding self-efficacy was 58.19 (10.48), it was 21.24 (5.69) for fear of coronavirus, 61.17 (10.78) for spouse postpartum social support, 21.36 (4.36) for perceived social support by family, 17.14 (5.16) for friends, 20.70 (4.63) for others, 8.03 (3.98) for anxiety and 7.49 (4.09) for depression (Tables 1 and 2).

The relationship between breastfeeding self-efficacy with different variables was studied based on univariate method and according to the results of independent t-test, one-way analysis of variance and Pearson correlation coefficient. The study results showed that the variables of education level $(0.05)$, time of first postpartum breastfeeding (0.02), type of infant feeding $(<0.001)$, tendency to breastfeed $(<0.001)$, fear of Covid-19 (0.05), age of newborn ( $<0.002)$, Anxiety $(<0.01)$, depression $(<0.001)$, spouse social support $(<0.04)$, and social support received from the family $(<0.05)$, were all significantly correlated with women's breastfeeding self-efficacy (Tables 1 and 2). These variables were included as independent variables in the multi variable linear regression model based on stepwise method. The multi variable regression model showed that the independent variables of spouse postpartum social support ( $\beta: 0.77)$, tendency to breastfeed ( $\beta$ : 0.171), depression ( $\beta$ : -0.09) ( $\beta 09 \beta$ : -0.086), and formula feeding along with breastfeeding ( $\beta$ : -0.11 ), were significant predictors of breastfeeding self-efficacy (Table 3 ).

\section{Discussion}


The aim of this study was to determine some predictors of breastfeeding self-efficacy during the Covid-19 pandemic. The mean and standard deviation of breastfeeding self-efficacy was $58.19 \pm 10.48$. In this study, the variables of spouse postpartum social support and breastfeeding intention were directly correlated to breastfeeding self-efficacy; and depression and using formula along with breastfeeding (non-exclusive breastfeeding) were negatively correlated with breastfeeding self-efficacy. Fear of coronavirus was not significantly correlated with breastfeeding self-efficacy. In several studies on breastfeeding self-efficacy, the mean score of breastfeeding self-efficacy was approximately similar to the present study. In a study by Moafi et al., the mean breastfeeding self-efficacy was 57.28 (40); Karbandi et al. found it as 47.10 (41) and Aghababaee et al. found it as 79.06 (42). In a study by Yang et al. in China on 571 postpartum mothers, the mothers reported moderate levels of breastfeeding selfefficacy (43).

The results of the present study showed that spouse postpartum social support has a significant correlation with breastfeeding self-efficacy in lactating women. In line with the obtained results, a study by Soltannejad et al. showed that the emotional and functional support of the spouse increases the mother's breastfeeding self-efficacy to breastfeed the baby and it can be concluded that the support of fathers and the subsequent increase in breastfeeding - no matter how small it might be - may increase the general public health (44). In a study by Eslahi et al., there was an inverse relationship between the support received from spouse and the postpartum depression (45). Maternal depression in the postpartum period is one of the factors that can negatively affect breastfeeding self-efficacy. Also, in a study by Khanzadeh et al., counseling the couples increased spouse support and its perception by the mother and consequently increased the attachment between mother and baby (46). In this regard, Zhu et al. have also shown that social support perceived by mothers and receiving attention from important people such as the spouse, mother, and friends, in addition to previous breastfeeding experience and learning by observing the breastfeeding practice of others, can be included as factors associated with increasing breastfeeding self-efficacy in Chinese women (47).

In a study by Moafi et al., breastfeeding self-efficacy was the most effective factor in predicting exclusive breastfeeding in the third month after delivery and could increase the chance of exclusive breastfeeding by 1.04 (3). McQueen et al. cited breastfeeding self-efficacy as a predictor of breastfeeding duration and exclusivity (48). In a study by Glassman et al., a higher breastfeeding self-efficacy of 0.38 , increased the exclusive breastfeeding level (49). Bastani and Rahmatnejad reported the breastfeeding self-efficacy in women with exclusive breastfeeding as 53.64, and in women with non-exclusive breastfeeding as 46.11 . People on exclusive breastfeeding had a higher breastfeeding self-efficacy score than those on nonexclusive breastfeeding (50). The findings of that study are in line with the present study and confirm that exclusive breastfeeding increases the breastfeeding self-efficacy. Because the today's health care system focuses on postpartum care - including exclusive breastfeeding - it is expected that the breastfeeding selfefficacy to increase relative to the past.

According to the results of the research, having the intention to breastfeed was another variable that predicted the breastfeeding self-efficacy in this study, which means that breastfeeding self-efficacy was 
higher in mothers who already intended to breastfeed. The results of the study by Moafi et al. also showed a significant relationship between the factor of making a decision for breastfeeding duration and breastfeeding self-efficacy (40). Also, in another study, Moafi et al. showed that mothers who chose exclusive breastfeeding before pregnancy were more likely to continue exclusive breastfeeding in the third month after delivery (3). Loke and Chan reported that exclusive breastfeeding would increase if more than 6 months had passed since the time that women had decided to breastfeed exclusively (51). In fact, it can be concluded that when a mother is predetermined to breastfeed, she tries harder to achieve her goal and feels more confident in her ability to breastfeed.

Giving supplements along with mother's breast milk can also affect breastfeeding self-efficacy. In the present study, breastfeeding self-efficacy was reduced in mothers who used formula feeding along with breastfeeding. In a study conducted by Zubaran et al. in Brazil, mothers who used combined breastfeeding (breast milk plus formula) showed higher scores on the postpartum depression scale and the postpartum depression screening scale (PDSS). Also, breastfeeding self-efficacy scores for mothers who were exclusively fed by breast milk was higher and was inversely related to depression (52). The results of the present study also showed that depression in breastfeeding mothers negatively affected breastfeeding self-efficacy. In a study by Coo et al., high levels of depression symptoms during pregnancy were associated with non-exclusive breastfeeding in the first three months after delivery. Also, in the first three months after delivery, high levels of anxiety and depression were associated with breastfeeding. This study concluded that both depression and anxiety of the mother have a negative effect on breastfeeding ability (53). In a study in the Maldives, Abdul Raheem et al. found that prenatal depression at the week 36 of pregnancy was associated with a delayed initiation of breastfeeding; and postpartum depression was associated with a shorter duration of exclusive breastfeeding or any type of breastfeeding (54).

In a study by Stark et al. out of 2,871 women under study, 302 (10.5\%) showed positive signs of prenatal depression. Women with prenatal depression were less likely to start breastfeeding and less likely to continue breastfeeding after 6 weeks of delivery. Prenatal depression was significantly associated with a reduction in continued breastfeeding (55). In a study by Aghaee et al., 30.4\% of non-breastfeeding mothers had depression. In that study, the presence of some degree of depression in the studied samples and also, the existence of a relationship between maternal depression and breastfeeding status, showed the importance of screening for depression during breastfeeding (56). These findings suggest that depression is negatively correlated with breastfeeding performance, and that mothers who suffer from depression symptoms may have less confidence in their ability to breastfeed, and that prenatal depression is a significant factor in early cessation of breastfeeding. Early detection of maternal mental health problems during pregnancy is essential to enhance the mother's emotional level and prevent breastfeeding problems. As a result, further interventions to improve breastfeeding should include assessing maternal mental health, and controlling pre- and postpartum depression in mothers to encourage them to start breastfeeding early, and breastfeed for a longer period. 
Although the findings of previous studies are similar to the findings of the present research in terms of mean breastfeeding self-efficacy and its predictors, it is noteworthy that the present study was carried out during the Covid-19 pandemic. Given that the Covid-19 pandemic is a critical condition, however, it is different from the effect that other crises and epidemics have on breastfeeding. According to the results, although the scores obtained from the fear of Covid-19 scale were relatively high in breastfeeding women, no correlation was found between breastfeeding self-efficacy and fear of Covid-19. It can be concluded that during the Covid-19 pandemic, mothers tried to maintain breastfeeding by following health protocols in order to boost their infant's immune system due to the existing conditions and their fear that their baby might catch Covid-19. A study in Ethiopia following the HIV epidemic found that HIVpositive mothers had a strong fear of breastfeeding that was disproportionate to documented evidence of transmission risk (25). Although infectious diseases have emerged at different ages in history, globalization in recent years has facilitated the spread of pathogens such as HIV, Ebola, Zika, and H1N1, resulting in global epidemics (57). This has further complicated the control of infections, which has led to significant political, economic and psychological outcomes and immediate public health challenges (58).

Fear is an adaptive reaction to danger. However, when the threat is uncertain and persistent, such as the coronavirus disease epidemic, fear can become chronic and severe (59). Patients with or suspected of Covid-19 infection may experience severe emotional and behavioral reactions such as fear, impatience, loneliness, anxiety, insomnia, or anger (60). Such conditions can lead to disorders such as depression, anxiety (including panic attacks and post-traumatic stress disorder), psychosis, or paranoia, and can even lead to suicide (61). In some cases, uncertainty about infection and death or the infection of family and friends can exacerbate bad temper (60). In the present study, although there was no statistically significant relationship between fear of Covid-19 and breastfeeding self-efficacy, but the relationship between anxiety and depression with breastfeeding self-efficacy could be a reflection of the psychological effects of fear of Covid-19, which in the present research showed itself as depression. The results also showed that depression in breastfeeding mothers could reduce breastfeeding self-efficacy in mothers.

\section{Strengths and Weaknesses of the Research}

One of the strengths of the present research is the study of breastfeeding status and breastfeeding selfefficacy during the Covid-19 pandemic crisis. By making use of an appropriate sample size and appropriate statistical methods, the present study has strived to simultaneously evaluate some predictors of breastfeeding self-efficacy during the Covid-19 pandemic. However, the cross-sectional nature of the research and use of questionnaires and also the self-report method are some of the limitations of the present study.

\section{Conclusion}

Based on the results of the present research, spouse postpartum social support and having the intention of breastfeeding, with a positive effect; and having depression and simultaneous use of formula in infant 
feeding, with a negative effect; are predictors of the women's breastfeeding self-efficacy during the Covid19 pandemic. It seems that it is possible to improve breastfeeding conditions through counseling with the aim of improving spouse support, enhancing the breastfeeding intention, and reducing depression.

\section{Declarations}

\section{Ethics approval and consent to participate:}

The research is approved by the Research Review Board at Qazvin Faculty of Nursing and Midwifery (IR.QUMS.REC.1399.079 at the Human Ethics Committee at Qazvin University of Medical Sciences). The permissions to access the health and medical centers have been obtained from the authorities in Qazvin University of Medical Sciences. Then, the researcher will introduce herself to the participants. After introducing the research objectives, the confidentiality of data maintenance and the freedom to withdraw from the study, the informed consent form will be signed by the participants who are willing to participate in this study.

\section{Consent for publication:}

Not applicable

\section{Availability of data and material:}

data will provided through email to corresponding author.

\section{Competing interests:}

None to declare

\section{Funding:}

Qazvin University of Medical Sciences financially support the project, but funding body does not have any role in design, data collection, data analysis and interpretation of findings.

\section{Authors' contributions:}

All authors contributed to the conception and design of the study. MAB, NB drafted the manuscript. ZA, $M A B$ and NB provided contributions to the literature review and substantially edited the primary manuscript and prepared the final version of the manuscript. All authors revised the manuscript, agreed to be fully accountable for ensuring the integrity and accuracy of the study, and read and approved the final version of the manuscript to be published. All the authors met the criteria for authorship, and they are listed as co-authors on the title page.

\section{Acknowledgements:}


Vice chancellor (Research) of Qazvin University of Medical Sciences has provided financial support to this project.

\section{References}

1. Organization WH. Global strategy for infant and young child feeding: World Health Organization; 2003.

2. Kornides M, Kitsantas P. Evaluation of breastfeeding promotion, support, and knowledge of benefits on breastfeeding outcomes. Journal of Child Health Care. 2013;17(3):264-73.

3. Moafi F, Momeni M, Yeke Falah Z, Asgari S, Hajnasiri H. Assessment of Breastfeeding Self-Efficacy and Patterns and its Predictors in Mothers Living in Qazvin Province. The J Urmia Nurs Midwifery Fac. 2018;15(10):777-87.

4. Rahmatnejad L, Bastani F. Factors associated with discotinuation of exclusive breast feeding by first time mothers. Iran Journal of Nursing. 2011;24(71):42-53.

5. Organization WH. Global Nutrition Targets 2025: Breastfeeding policy. WH O Publ. 2014:1-7.

6. Barona-Vilar C, Escribá-Agüir V, Ferrero-Gandía R. A qualitative approach to social support and breastfeeding decisions. Midwifery. 2009;25(2):187-94.

7. Yılmaz E, Öcal FD, Yılmaz ZV, Ceyhan M, Kara OF, Küçüközkan T. Early initiation and exclusive breastfeeding: Factors influencing the attitudes of mothers who gave birth in a baby-friendly hospital. Turkish journal of obstetrics and gynecology. 2017;14(1):1.

8. Baud D, Qi X, Nielsen-Saines K, Musso D, Pomar L, Favre G. Real estimates of mortality following COVID-19 infection. The Lancet infectious diseases. 2020.

9. Dennis C-L. Theoretical underpinnings of breastfeeding confidence: a self-efficacy framework. Journal of human lactation. 1999;15(3):195-201.

10. Sinsuksai N, Nuampa S, Chanprapaph P. Factors predicting 6-month-exclusive breastfeeding in mothers with cesarean section. Nursing Science Journal of Thailand. 2017;35(1):14-22.

11. Azhari S, Baghani R, Akhlaghi F, Ebrahimzadeh S, Salehi J. Comparing the effects of hands-on and hands-off breastfeeding methods on self-efficacy in primiparous mothers. Journal Of Sabzevar University Of Medical Sciences. 2011;17(4 (58)):-.

12. Dodt RCM, Joventino ES, Aquino PS, Almeida PC, Ximenes LB. An experimental study of an educational intervention to promote maternal self-efficacy in breastfeeding. Revista latino-americana de enfermagem. 2015;23(4):725-32.

13. Entwistle F, Kendall S, Mead M. Breastfeeding support-the importance of self-efficacy for lowincome women. Maternal \& child nutrition. 2010;6(3):228-42.

14. Dennis CLE. Identifying predictors of breastfeeding self-efficacy in the immediate postpartum period. Research in nursing \& health. 2006;29(4):256-68.

15. Hasanpoor S, Bani S, Ansari S, Ebrahimi H. Measuring breastfeeding self-efficacy among pregnant women referred to health centers of Ahvaz. 2010. 
16. Varaei S, Mehrdad N, Bahrani N. The Relationship between Self-efficacy and Breastfeeding, Tehran, Iran. Hayat. 2009;15(3).

17. O'Brien M, Buikstra E, Hegney D. The influence of psychological factors on breastfeeding duration. Journal of advanced nursing. 2008;63(4):397-408.

18. Kools EJ, Thijs C, Kester AD, de Vries H. The motivational determinants of breast-feeding: predictors for the continuation of breast-feeding. Preventive medicine. 2006;43(5):394-401.

19. World Health Organization. (2020). Coronavirus disease 2019 (COVID-19) situation report-34. Geneva SWHOhwwidd-s.

20. Hu Z, Song C, Xu C, Jin G, Chen Y, Xu X, et al. Clinical characteristics of 24 asymptomatic infections with COVID-19 screened among close contacts in Nanjing, China. Science China Life Sciences. 2020:1-6.

21. Lin C-Y. Social reaction toward the 2019 novel coronavirus (COVID-19). Social Health and Behavior. 2020;3(1):1.

22. Pappas G, Kiriaze I, Giannakis P, Falagas M. Psychosocial consequences of infectious diseases. Clinical microbiology and infection. 2009;15(8):743-7.

23. Li Q, Guan X, Wu P, Wang X, Zhou L, Tong Y, et al. Early transmission dynamics in Wuhan, China, of novel coronavirus-infected pneumonia. New England Journal of Medicine. 2020.

24. Huang C, Wang Y, Li X, Ren L, Zhao J, Hu Y, et al. Clinical features of patients infected with 2019 novel coronavirus in Wuhan, China. The Lancet. 2020;395(10223):497-506.

25. Koricho AT, Moland KM, Blystad A. Poisonous milk and sinful mothers: the changing meaning of breastfeeding in the wake of the HIV epidemic in Addis Ababa, Ethiopia. International breastfeeding journal. 2010;5(1):12.

26. Orvos JM. CDC guidance on coronavirus in pregnant, breastfeeding women. 2020.

27. Green SB. How many subjects does it take to do a regression analysis. Multivariate behavioral research. 1991;26(3):499-510.

28. Dennis C-L, Brown HK, Brennenstuhl S. The Postpartum Partner Support Scale: Development, psychometric assessment, and predictive validity in a Canadian prospective cohort. Midwifery. 2017;54:18-24.

29. Eslahi Z, Alimoradi Z, Bahrami N, Lin C-Y, Griffiths MD, Pakpour AH. Psychometric Properties of Postpartum Partner Support Scale - Persian Version. Nursing Open. 2019;Accepted.

30. Zimet GD, Dahlem NW, Zimet SG, Farley GK. The Multidimensional Scale of Perceived Social Support. Journal of Personality Assessment. 1988;52(1):30-41.

31. Bruwer B, Emsley R, Kidd M, Lochner C, Seedat S. Psychometric properties of the Multidimensional Scale of Perceived Social Support in youth. Comprehensive psychiatry. 2008;49(2):195-201.

32. Salimi A, JOUKAR B, NIKPOUR R. Internet and communication: Perceived social support and loneliness as antecedent variables. 2009. 
33. Zigmond AS, Snaith RP. The hospital anxiety and depression scale. Acta psychiatrica scandinavica. 1983;67(6):361-70.

34. Bjelland I, Dahl AA, Haug TT, Neckelmann D. The validity of the Hospital Anxiety and Depression Scale: an updated literature review. Journal of psychosomatic research. 2002;52(2):69-77.

35. Montazeri A, Vahdaninia M, Ebrahimi M, Jarvandi S. The Hospital Anxiety and Depression Scale (HADS): translation and validation study of the Iranian version. Health and quality of life outcomes. 2003;1(1):1-5.

36. Ahorsu DK, Lin C-Y, Imani V, Saffari M, Griffiths MD, Pakpour AH. The Fear of COVID-19 Scale: Development and Initial Validation. International Journal of Mental Health and Addiction. 2020:1.

37. Dennis C-L, Hodnett E, Gallop R, Chalmers B. The effect of peer support on breast-feeding duration among primiparous women: a randomized controlled trial. Cmaj. 2002;166(1):21-8.

38. Dennis CL. The breastfeeding self-efficacy scale: Psychometric assessment of the short form. Journal of Obstetric, Gynecologic, \& Neonatal Nursing. 2003;32(6):734-44.

39. Bastani F, Rahmatnejad L, Jahdi F, Haghani H. Breastfeeding self efficacy and perceived stress in primiparous mothers. Iran Journal of Nursing. 2008;21(54):9-24.

40. Moafi F, H. Hajnasiri H, Hosseini T, Alimoradi Z, Bajalan Z. Breastfeeding Self-Efficacy and Its Associated Factors in Women who Gave Birth in Kosar Hospital of Qazvin in 2016-2017: A Descriptive Study. Journal of Rafsanjan University of Medical Sciences. 2019;17(11):1003-16.

41. karbandi S, Hosseini SM, Masoudi R, Mamori GA. The effect of relaxation training on breastfeeding self-efficacy of mothers with preterm infants: A randomized clinical trial. Journal of Clinical Nursing and Midwifery. 2014;3(2):37-45.

42. Aghababaei S, Khodakarami B, Farhadian M, Kamali M. Effectivness of Counseling on Mother's Breastfeeding Self-Efficacy. Avicenna Journal of Nursing and Midwifery Care. 2020;28(4):84-91.

43. Yang $X$, Gao L-I, Ip W-Y, Chan WCS. Predictors of breast feeding self-efficacy in the immediate postpartum period: A cross-sectional study. Midwifery. 2016;41:1-8.

44. SOltannejad N RM, Parvizi S, Kazemnejad A. Impact on the education fathers to support mothers in breastfeeding self ef-ficacy. 2017.

45. Eslahi Z, Bahrami N, Allen KA, Alimoradi Z. Spouse's social support in the postpartum period, predictors and its relationship with postpartum depression in a sample of Iranian primiparous women. International Journal of Gynecology \& Obstetrics. 2020.

46. khanzadeh z, Mogaddam Tabrizi F. The Effect of Supportive couple Counsulleing on Percived Spouse's Support and Maternal Attachment in Parturients Referring to Health Centers of Urmia University of Medical Sciences in 2018-19. Avicenna Journal of Nursing and Midwifery Care. 2020;28(2):0-.

47. Zhu J, Chan WCS, Zhou X, Ye B, He H-G. Predictors of breast feeding self-efficacy among Chinese mothers: A cross-sectional questionnaire survey. Midwifery. 2014;30(6):705-11. 
48. McQueen K, Sieswerda LE, Montelpare W, Dennis CL. Prevalence and factors affecting breastfeeding among Aboriginal women in Northwestern Ontario. Journal of Obstetric, Gynecologic \& Neonatal Nursing. 2015;44(1):51-68.

49. Glassman ME, McKearney K, Saslaw M, Sirota DR. Impact of breastfeeding self-efficacy and sociocultural factors on early breastfeeding in an urban, predominantly Dominican community. Breastfeeding Medicine. 2014;9(6):301-7.

50. Rahmatnejad L, Bastani F. An investigation of Breast Feeding Self Efficacy and its Relationship with exclusive breast feeding. Alborz University Medical Journal. 2012;1(1):31-6.

51. Loke AY, Chan LKS. Maternal breastfeeding self-efficacy and the breastfeeding behaviors of newborns in the practice of exclusive breastfeeding. Journal of Obstetric, Gynecologic \& Neonatal Nursing. 2013;42(6):672-84.

52. Zubaran C, Foresti K. The correlation between breastfeeding self-efficacy and maternal postpartum depression in southern Brazil. Sexual \& Reproductive Healthcare. 2013;4(1):9-15.

53. Coo S, García MI, Mira A, Valdés V. The Role of Perinatal Anxiety and Depression in Breastfeeding Practices. Breastfeeding Medicine. 2020.

54. Abdul Raheem R, Chih HJ, Binns CW. Maternal Depression and Breastfeeding Practices in the Maldives. Asia Pacific Journal of Public Health. 2019;31(2):113-20.

55. Stark E, Shim J, Ross C, Miller ES. The Impact of Perinatal Depression on Breastfeeding Rates [15K]. Obstetrics \& Gynecology. 2018;131:122S-3S.

56. Agayee A, Savabi M, Kheirabadi G. The Association between Maternal Depression and Lactation Status during the 24 Months after Delivery. Journal of Research in Behavioural Sciences. 2015;13(4):581-6.

57. Tucci V, Moukaddam N, Meadows J, Shah S, Galwankar SC, Kapur GB. The forgotten plague: psychiatric manifestations of ebola, zika, and emerging infectious diseases. Journal of global infectious diseases. 2017;9(4):151.

58. Ferguson N, Laydon D, Nedjati Gilani G, Imai N, Ainslie K, Baguelin M. Report 9: Impact of nonpharmaceutical interventions (NPIs) to reduce COVID19 mortality and healthcare demand [Internet]. 2020 Mar [cited 2020 Apr 5].

59. Mertens G, Gerritsen L, Salemink E, Engelhard I. Fear of the coronavirus (COVID-19): Predictors in an online study conducted in March 2020. 2020.

60. Shigemura J, Ursano RJ, Morganstein JC, Kurosawa M, Benedek DM. Public responses to the novel 2019 coronavirus (2019-nCoV) in Japan: Mental health consequences and target populations. Psychiatry and clinical neurosciences. 2020;74(4):281.

61. Xiang Y-T, Yang Y, Li W, Zhang L, Zhang Q, Cheung T, et al. Timely mental health care for the 2019 novel coronavirus outbreak is urgently needed. The Lancet Psychiatry. 2020;7(3):228-9.

\section{Tables}


Distribution of socio-demographic variables and results of univariable analysis to determine association of these variable with Breastfeed Self Efficacy as independent variable

\begin{tabular}{|c|c|c|c|c|c|}
\hline \multirow[t]{2}{*}{ Variables } & & \multirow[t]{2}{*}{ Range } & \multirow[t]{2}{*}{ Mean (SD) } & \multicolumn{2}{|l|}{$\begin{array}{l}\text { Pearson } \\
\text { correlation }\end{array}$} \\
\hline & & & & $r$ & $\begin{array}{l}\mathrm{p} \\
\text { value }\end{array}$ \\
\hline Age (year) & & $16-45$ & $\begin{array}{l}29.68 \\
(5.66)\end{array}$ & -0.04 & 0.48 \\
\hline Spouse Age (year) & & $21-55$ & $\begin{array}{l}34.27 \\
(5.47)\end{array}$ & -0.001 & 0.99 \\
\hline Birth weight (gram) & & $1320-5515$ & $\begin{array}{l}3284 \\
(512.49)\end{array}$ & -0.02 & 0.76 \\
\hline Neonate Age (month) & & $1-22$ & $5.02(4.67)$ & 0.17 & 0.002 \\
\hline Birth Gestational Age (weeks) & & $33-42$ & $\begin{array}{l}38.03 \\
(1.71)\end{array}$ & 0.05 & 0.36 \\
\hline Spiritual Beliefs & & $0-10$ & $9.02(1.85)$ & 0.003 & 0.95 \\
\hline FOC & & $9-35$ & $\begin{array}{l}21.24 \\
(5.69)\end{array}$ & -0.036 & 0.514 \\
\hline \multirow[t]{2}{*}{ HADS } & Anxiety & $0-21$ & $8.03(3.98)$ & -0.14 & 0.01 \\
\hline & Depression & $0-21$ & $7.49(4.09)$ & -0.19 & 0.001 \\
\hline Spouse Postpartum Support & & $24-80$ & $\begin{array}{l}61.17 \\
(10.78)\end{array}$ & 0.114 & 0.04 \\
\hline \multirow[t]{3}{*}{ MsPSS } & Family & $4-28$ & $\begin{array}{l}21.36 \\
(4.36)\end{array}$ & 0.11 & 0.05 \\
\hline & Friends & $4-28$ & $\begin{array}{l}17.14 \\
(5.16)\end{array}$ & -0.02 & 0.75 \\
\hline & others & $4-28$ & $\begin{array}{l}20.70 \\
(4.63)\end{array}$ & 0.06 & 0.26 \\
\hline \multirow[t]{2}{*}{ Breastfeed Self Efficacy } & & $17-70$ & $\begin{array}{l}58.19 \\
(10.48)\end{array}$ & & \\
\hline & & & No $(\%)$ & statistics & $\begin{array}{l}\mathrm{p} \\
\text { value }\end{array}$ \\
\hline \multirow[t]{3}{*}{ Education } & Below Diploma & & $52(16)$ & F: 3.12 & 0.05 \\
\hline & Diploma & & $117(36.1)$ & & \\
\hline & Academic & & $155(47.8)$ & & \\
\hline Spouse Education & Below Diploma & & $81(25)$ & F: 0.09 & 0.92 \\
\hline
\end{tabular}




\begin{tabular}{|c|c|c|c|c|}
\hline & Diploma & $106(32.7)$ & & \\
\hline & Academic & 13742.30 & & \\
\hline Job & Housewife & $280(86.4)$ & $\mathrm{t}: 0.54$ & 0.59 \\
\hline & Employed & $44(13.6)$ & & \\
\hline Spouse Job & Unemployed & $26(8)$ & $\mathrm{t}: 1.55$ & 0.12 \\
\hline & Employed & $298(92)$ & & \\
\hline Economic Status & Week & $52(16)$ & $F: 2.61$ & 0.08 \\
\hline & Fair & $218(67.3)$ & & \\
\hline & Good & $54(16.7)$ & & \\
\hline Neonate Gender & Girl & $153(47.2)$ & t: 0.86 & 0.393 \\
\hline & Boy & $171(52.8)$ & & \\
\hline Type of Delivery & NVD & $148(45.7)$ & t: 0.18 & 0.86 \\
\hline & CS & $176(54.3)$ & & \\
\hline First Breastfeeding after & less than 1 hour & $210(64.8)$ & $\mathrm{t}: 2.30$ & 0.02 \\
\hline & More than 1 hour & $114(35.2)$ & & \\
\hline Skin Contact after delivery & No & $95(29.3)$ & $\mathrm{t}:-0.08$ & 0.94 \\
\hline & Yes & $229(70.7)$ & & \\
\hline Neonate Hospitalization & No & $260(80.2)$ & $\mathrm{t} ; 1.52$ & 0.13 \\
\hline & Yes & $64(19.8)$ & & \\
\hline Neonate Feeding & Exclusive breastfeeding & $173(53.4)$ & $F: 58.37$ & $<0.001$ \\
\hline & Formula & $12(3.7)$ & & \\
\hline & Breastfeed + Formula & $60(18.5)$ & & \\
\hline & $\begin{array}{l}\text { Breastfeed + Complementary } \\
\text { feeding }\end{array}$ & $79(24.4)$ & & \\
\hline Previous experience of Breast & No & $176(54.3)$ & $\mathrm{t}:-1.05$ & 0.30 \\
\hline & Yes & $148(45.7)$ & & \\
\hline Intent to Breastfeed & No & $18(5.6)$ & 29.36 & $<0.001$ \\
\hline & Yes & $259(79.9)$ & & \\
\hline & Undetermined & $47(14.5)$ & & \\
\hline Gravid & 1 & $157(48.5)$ & r: 0.06 & 0.28 \\
\hline
\end{tabular}

Page 17/19 


\begin{tabular}{|c|c|c|c|c|}
\hline & & & & \\
\hline & 2 & $102(31.5)$ & & \\
\hline & $\geq 3$ & $65(20.1)$ & & \\
\hline \multirow[t]{3}{*}{ Child No } & 1 & $174(53.7)$ & \multirow[t]{3}{*}{ r: 0.06} & \multirow[t]{3}{*}{0.33} \\
\hline & 2 & $108(33.3)$ & & \\
\hline & $\geq 3$ & $42(13)$ & & \\
\hline \multirow[t]{4}{*}{ Contraception } & WD & $208(64.2)$ & \multirow[t]{4}{*}{$F: 0.32$} & \multirow[t]{4}{*}{0.81} \\
\hline & IUD & $12(3.7)$ & & \\
\hline & Condom & $79(24.4)$ & & \\
\hline & Hormonal & $25(7.7)$ & & \\
\hline \multirow[t]{3}{*}{ Covid Status } & Not infected & $295(91)$ & \multirow[t]{3}{*}{$F: 3.06$} & \multirow[t]{3}{*}{0.05} \\
\hline & Infected \& treated & $23(7.1)$ & & \\
\hline & Suspicious & $6(1.9)$ & & \\
\hline
\end{tabular}




\section{Table 2}

Results of multivariable linear regression model considering Breastfeed Self Efficacy as dependent variable

\begin{tabular}{|c|c|c|c|c|}
\hline & \multicolumn{2}{|c|}{$\begin{array}{l}\text { Unstandardized } \\
\text { Coefficients }\end{array}$} & \multirow{2}{*}{$\begin{array}{l}\text { Standardized } \\
\text { Coefficients } \\
\text { Beta }\end{array}$} & \multirow[t]{2}{*}{ Sig. } \\
\hline & $\mathrm{B}(95 \% \mathrm{Cl})$ & $\begin{array}{l}\text { Std. } \\
\text { Error }\end{array}$ & & \\
\hline Spouse Post-Partum Support & $\begin{array}{l}0.73(0.68 \\
0.79)\end{array}$ & 00.03 & 0.77 & .000 \\
\hline Intent To Breastfeed & $\begin{array}{l}8.60(5.88 \\
11.32)\end{array}$ & 1.38 & 0.17 & .000 \\
\hline $\begin{array}{l}\text { Neonate Feeding }=\text { Breastfeed }+ \\
\text { Formula (vs. EBF) }\end{array}$ & $\begin{array}{l}-10.75(-13.75 \\
-7.75)\end{array}$ & 1.53 & -.09 & .000 \\
\hline Depression & $\begin{array}{l}0.74(0.47 \\
1.01)\end{array}$ & .14 & 0.11 & .000 \\
\hline \multirow[t]{4}{*}{ Model Summary } & \multicolumn{4}{|l|}{ R: 0.98} \\
\hline & \multicolumn{4}{|l|}{$\mathrm{R}^{2}: 0.96$} \\
\hline & \multicolumn{4}{|c|}{ Adjusted $\mathrm{R}^{2}: 0.96$} \\
\hline & \multicolumn{4}{|c|}{ Durbin-Watson: 1.79} \\
\hline \multicolumn{5}{|c|}{ a. Dependent Variable: Breastfeed Self Efficacy } \\
\hline \multicolumn{5}{|c|}{ b. Linear Regression through the Origin } \\
\hline
\end{tabular}

Table 3 is not available with this version. 